This is a pre-copy-editing, author-produced PDF of an article accepted following peer review for publication in the Journal of Consumer Culture (JCC)

\title{
Locking-down instituted practices: Understanding sustainability in the context of 'domestic' consumption in the remaking
}

\section{Authors}

Torik Holmes (HolmesT2@cardiff.ac.uk) School of Geography and Planning, Cardiff University Carolynne Lord (c.lord@lancaster.ac.uk) School of Computing and Communications, Lancaster University

Katherine Ellsworth-Krebs (k.ellsworth-krebs@lancaster.ac.uk) Lancaster Institute of Contemporary Arts, Lancaster University

\section{Abstract}

Due to the COVID-19 pandemic, governments around the world placed communities under 'lockdown'. Various practices of consumption were uprooted from their instituted settings and re-rooted in homes. This unprecedented reorganisation of normality resulted in increased instances of domestic consumption as practices occurring in offices, gyms and eateries were forced into homes, demanding the acquisition of materials and altering expectations of what homes are for. This article contributes to literature on COVID-19 and practice-based consumption research by complicating optimistic narratives about the potential for this disruption to downsize the consumer economy. Combining qualitative household interviews, with secondary data about wider trends, and historical reflection on changes in the meaning of the 'home' in the UK, we reveal how the re-rooting of instituted practices structures material acquisition and spikes desire for more domestic space. Recognising that professional practices and institutions have taken on increasing significance for domestic consumption, with stay-athome orders blurring boundaries between home, work, and leisure, we conclude by arguing that future research and sustainability policy should attend more to the institutional qualities of practices.

Keywords: sustainability, theories of practice, domestic consumption, instituted qualities, lockdown

\section{Introduction}

It is broadly acknowledged that the disruption brought about by the COVID-19 pandemic has profound implications for climate change and sustainable consumption. Some have suggested that this moment represents an opportunity for "downsizing the consumer economy" (Cohen, 2020: 1). In this regard, the pandemic has been seen as an occasion to 'reset' and take steps towards addressing issues of climate change and poverty (Markard and Rosenbloom, 2020). These suggestions have been accompanied with evidence of unprecedented reductions in air pollution (Chen et al., 2020). With the smog clearing around cities and wildlife returning, the benefits of the new 'normal' have been considered by sustainability researchers, with attention drawn, for example, to the demise of the commute and international travel (Sovacool et al., 2020). Dramatic decreases in travelling were, however, coupled with spikes in material consumption as consumers 'panic bought' and acquired new materials for 'lockdown' life (BBC, 2020; Hall et al., 2020; Jahshan, 2020; Wood, 2020; Wood and Partridge, 2020). These trends, 
This is a pre-copy-editing, author-produced PDF of an article accepted following peer review for publication in the Journal of Consumer Culture (JCC)

like the falling frequency of various mobilities, were part and parcel of stay-at-home orders and related to spatial and temporal 'displacements' of consumption (Hall et al., 2020).

In this paper, we contribute to academic debates on what COVID-19 means for sustainability transitions by complicating the 'downsizing' narrative. Taking inspiration from theories of social practice (Reckwitz, 2002; Warde, 2005; Shove et al., 2012; Blue and Spurling, 2017), we examine how bundles of practice, typically occurring outside of homes (office working, fitness, and the working lunch), anchor in domestic sites, helping to constitute forms of material consumption. This is done by drawing together insights generated through seventeen qualitative interviews with UK households and engagement with secondary data concerning wider trends in consumption. The home is conceptualised in this paper as a site of convergence, infused with various material-spatial and affective instituted qualities of practices that structure patterns of consumption. We argue that the patterns of resource use that transpired during lockdown did not only happen within and for the sake of practices (Warde, 2005; Shove et al., 2012; Shove and Walker, 2014), but were emergent too of attempts to (re)produce social sites imbued with qualities and expectations resultant of various instituted histories and settings.

We begin by setting out the theoretical framing of the paper. After discussing our research approach and methods, we initiate the analysis by emphasising the 'new' materials that flowed into homes as part of offices, gyms or eateries being squeezed into and remade across domestic spaces. Next we explore the affective qualities that were sought out, arguing that certain expectations of privacy and comfort emerge from practices previously taking place in other institutional sites. Drawing insights together, we connect attempts to recreate instituted settings within homes not only with spikes in different forms of material consumption but also with a demand for more physical space. In the final empirical section, we take the previouslyestablished bundle of the working lunch to demonstrate how even relatively obdurate arrangements can be disrupted when performed away from their specialised sites. In the penultimate section, we discuss a set of implications and possible responses. To conclude, we argue that research and policy would benefit from interpreting and targeting the instituted qualities of practice bundles on the move and shifted due to locking-down. The sooner this is done, the greater the opportunity to challenge problematic trends in consumption before they spread, stick, and become more obdurate and resistant to change.

\section{Practices and consumption}

Taking inspiration from theories of social practice, we approach consumption as an outcome of the instituted qualities and ordering of practices (Schatzki, 1996, 2002; Warde, 2005; Shove et al., 2012). Though "[t] heories of practice are very heterogeneous" (Warde, 2005: 132), there is a shared understanding that neither society 'at large' (homo sociologicus) nor individual actors (homo economicus) should form the subject of study (Giddens, 1987; Schatzki, 1996, 2002; Warde, 2005; Shove et al., 2012). Instead, practices, "[...] as the central phenomenon in social life", are treated as the principal units of empirical enquiry (Schatzki, 1996: xi).

Schatzki (1996: 89) defines a "practice [as...] a temporally unfolding and spatially dispersed nexus of doings and sayings", which consist of "embodied, materially mediated arrays of human activity centrally organized around shared practical understanding" (Schatzki, 2001a: 2). Examples include cooking, watching TV, riding a bicycle, and driving. Practices are further 
This is a pre-copy-editing, author-produced PDF of an article accepted following peer review for publication in the Journal of Consumer Culture (JCC)

understood to combine to form 'bundles'. "Practices bundle through states of affairs that largely come to pass through the carrying-on of the practices involved at particular times and places" (Schatzki, 1996: 201). The instituted site of a family home, for instance, typically consists "in a specific bundling together of (often local versions of) such practices as those of sleeping, cooking, rearing, recreation, and hygiene" (Schatzki, 1996: 201).

Situating the concept of practice at the heart of the dynamics of consumption and provision, Blue (2017: 5) writes that the "spatiotemporal extension of practices is what reproduces everyday and 'normal' ways of living and consuming". Consumption is, in this way, understood to occur within and for the sake of practices, and focus has been centred on the "routine, ordinary, collective, [and] conventional nature of much consumption" (Warde, 2005: 145-146). Based on this practice-oriented framing, several prominent themes emerge concerning qualities of practice, bundles and consumption, which include, among others, material-spatial and affective dimensions. We briefly discuss these key themes in reference to the idea that practices are 'instituted' phenomenon (Warde, 2005: 146). This idea has implications for how we approach the uprooting and re-rooting of practice bundles and their related qualities into homes during lockdown.

'Instituted' material-spatial and affective qualities of practice and consumption

Practice theorists, including Gherardi (2000), Nicolini (2011) and Schatzki (2005, 2006), have articulated accounts of institutions that "are rooted in practice" (Blue, 2017: 8). However, we specifically follow Warde (2005) in framing all social practices as organised socio-material arrangements that always have instituted histories, which shape future action:

Practices have a trajectory or path of development, a history. Moreover, that history will be differentiated, for the substantive forms that practices take will always be conditional upon the institutional arrangements characteristic of time, space and social context, for example of household organization, dominant modes of economic exchange and cultural traditions. 'Why do people do what they do?', and 'how do they do those things in the way that they do?' are perhaps the key sociological questions concerning practices, the answers to which will necessarily be historical and institutional. (Warde, 2005: 139-140)

This quote supports our idea that patterns of consumption connected with the lockdown should be approached as outcomes of the uprooting and re-rooting of multiple instituted practices (e.g., working, the working lunch, and keeping fit), with various qualities, inside homes. We group these qualities under two analytical categories: 1) 'material-spatial'; 2) 'affective'.

In line with the material turn and particularly with developments within Science and Technology Studies (STS) (Latour and Woolgar, 1979; Akrich, 1992), materials of practice are understood to play an active role in constituting consumption (Shove and Pantzar, 2005; Shove et al., 2012). This is because "things are centrally and unavoidably implicated in the production and reproduction of practice" (Shove and Pantzar, 2005: 45). Materials involved in laundry routines (Jack, 2013), food provisioning (Hand and Shove, 2007; Rinkinen et al., 2017), and space heating and cooling (Gram-Hanssen, 2011; Rinkinen and Jalas, 2016; Spurling, 2018) have, for instance, been shown to standardise and to an extent 'lock in' expectations and 
This is a pre-copy-editing, author-produced PDF of an article accepted following peer review for publication in the Journal of Consumer Culture (JCC)

patterns of resource use. The historical emergence of the car and the evolution of driving as a practice are particularly telling in this regard: car designs, road building, the acquisition of space for parking and refuelling, and the redesign of homes, places of work, and more broadly rural and urban settings, have and continue to recursively constitute and standardise patterns of consumption and provision associated with this mode of transport (Sheller and Urry, 2000; Shove, 2016; Spurling, 2018).

As the example of the car suggests, materials of practices do not exist abstractly from space. Instead, materials and arrangements thereof help to make up 'sites of the social' (Schatzki, 2002). These sites are comprised of various 'doing-places' and 'settings' (Schatzki, 1991, 2002; Hui and Walker, 2018). A doing-place "is a place to X, e.g., a bed is a place to sleep, a table a place to eat, and a bus stop a place to catch the bus" (Schatzki, 1991: 655). "Settings are where the doing-places of multiple practices come together and intersect" (Hui and Walker, 2018: 23). A setting is thus a "loosely or tightly bundled totality of [doing-]places" (Schatzki, 1991: 655), which has "either barriers or a particular organisational structure demarcating" it (Hui and Walker, 2018: 23). Examples of settings pertinent to our analysis include rooms in homes, offices, and gyms. Crucially, such examples, and the doing-places that comprise them, are made up of and marked out by materials and arrangements thereof, both of which structure activity. It is in acknowledging such dynamics and the connections between materials, doingplaces, settings, social sites, and the ordering and performance of practices, that we, taking inspiration from Hui and Walker (2018) and Blue and Spurling (2017), refer to 'material-spatial' qualities of practice bundles.

Practices are also understood to guide and be guided by affective qualities (Reckwitz, 2002, 2017; Schatzki, 2001b, 2014). Schatzki's (2001b) conceptualisation of teleoaffective structures helps to explain why this is the case. Teleoaffective structures involve:

A range of acceptable or correct ends, acceptable or correct tasks to carry out for these ends, acceptable or correct beliefs (etc.) given which specific tasks are carried out for the sake of these ends, and even acceptable or correct emotions out of which to do so. (Schatzki, 2001b: 53).

Affective qualities, related emotions and desires, are thus understood to be structured by practices and connected to more widespread normative frames that are worked towards through performance (Welch, 2020).

As means of example, running is now related to self-improvement and personal health, yet, striving for this end can involve different emotions depending on the materials and settings of the activity (Hitchings and Latham, 2017). Running indoors and outdoors is very different. Inside performances may require a treadmill and be perceived as more 'relaxing' by enabling exercise to be scheduled without the potential to get lost or be put off by the weather. By contrast running outdoors may be preferred and pursued because it is 'energising' or 'cheap', yet for some, may require living in a suitable area with a nearby green setting, or additional materials such as additional clothing and/or a GPS tracker. As this example suggests, emotions and emotional expectations structure and are structured by patterns of material-spatial consumption. 
This is a pre-copy-editing, author-produced PDF of an article accepted following peer review for publication in the Journal of Consumer Culture (JCC)

Taking the ideas presented forward, we examine the constitution of homes as sites of consumption during the first UK lockdown - a period when bundles of practice, with histories typically rooted in other institutional settings, were uprooted and re-rooted. This investigation provides an opportunity to better understand the dynamics of locking-down, the implications for sustainability, and what is called for in response.

\section{Investigating 'locked-down' practices}

Our analysis is based on seventeen qualitative interviews with UK households in June and July 2020. We also draw on wider secondary data about trends in resource use during lockdown and historical reflections on changing practices. Interviewees were from various professional backgrounds and were recruited through social networks. The sampling approach aimed at achieving diversity across professions, household composition (e.g., living alone; couples; families) and housing types (e.g., flats; terraced houses; detached houses). This was done to explore varied experiences of lockdown. In total, eleven out of the seventeen interviews were with women, four were with men, and in two cases couples were interviewed together. The sample included four single people (one living with housemates), eight couples, and five families. Our interviewees were relatively young, with one in their late twenties, eleven in their thirties, three aged between forty and fifty-four, and two between fifty-five and seventy. The interviews were semi-structured, lasting up to ninety minutes, and took place over the phone or through video call. We discussed interviewees' everyday routines during lockdown and how the stay-at-home orders impacted working, eating, mobility, and leisure practices.

Our analysis is focused on office working, keeping fit and eating because these bundles of practice emerged during the interviews as key topics. While our sample included participants whose work was not office-based, the majority were, and the interviews provided rich insight in this regard. This is why we chose to focus on office working as opposed to other forms of working from home (WFH), such as running fitness classes online - though these other forms were also on the move. We have included job titles with pseudonyms when referring to participants to provide extra insight about their employment, and in part to acknowledge that our sample was relatively socio-economically privileged. For this reason, the analysis below does not reflect the extreme and unevenly distributed hardship many people experience(d) as a result of COVID-19 (Cheng et al., 2020; Nicola et al., 2020; Carethers, 2021; Phuong and Reanne, 2021). The relative socio-economic advantage of interviewees meant there was lively discussion of the acquisition of goods, the rearranging of doing-places and settings, and attempts to attain and produce affective qualities in the home than might have emerged in other contexts.

\section{'New' materialities}

Given the immediacy of the lockdown and the perception that it would end soon, many of our participants discussed reappropriating items that were ready-to-hand for purposes that they were not previously used for:

I was working from the kitchen table for the first two months [...], and I was finding I was getting a really stiff back every day because I was just sitting on a dining chair. I had my laptop propped up on a box file and two reams of paper so that it was at the correct height. (Charlotte, 40, administrator) 
This is a pre-copy-editing, author-produced PDF of an article accepted following peer review for publication in the Journal of Consumer Culture (JCC)

This jerry-rigging was necessitated due to the broader historical separation between sites of work and domestic life - a feature of the wider socio-economic ordering of everyday life over two centuries, distilled first in the creation of factories and later offices (Littler, 1987). Many homes were thus not adequately equipped for performances of office work when lockdown was announced. Instances of improvisation, like that noted by Charlotte, signalled attempts to quickly produce a setting within the home in the image of the office. Materials were, for example, assembled to achieve the 'correct height' - a historical standard engrained in office ergonomics and offices as material-spatial settings of work (Peteri, 2017).

As the quote from Charlotte also suggests, attempts to jerry-rig settings were not always effective, with bodies feeling the impact over time (e.g., stiff necks and/or knees). Once realisations set in that the lockdown was going to be a prolonged experience, participants discussed buying equipment as part of actively dissolving the historical boundaries between office work and home.

His work has paid for a desk and a chair [...] He was really uncomfy sitting down in the dining room. So that space [the spare bedroom] is now his, [and] it can feel like he's actually at work. (Sharron, 31, sales)

Some employers financed and/or provided the necessary equipment for performances of WFH, though this provision took different forms. Laptops, desktop computers, monitors, keyboards, mouses, desks and chairs, in cases, migrated from offices. In other cases, as in that evidenced above, new equipment was financed by employers. In others still, work depended on specialised digital networks of provision that had to be provided. The persistence of the lockdown led, in turn, to a circulation and anchoring of instituted materials across participants' homes, as they (and at times their employers) sought to remake more stable settings of practice in the image of the office.

Our findings reflect broader trends in society. With much office space having been empty since March 2020, 47\% of employees in the UK did some WFH in April (ONS, 2020a). This is a sizable increase from 5\% of the employed population mainly WFH in 2019 (ONS, 2020b). Mirroring this increase, worldwide sales of computers increased by $11.2 \%$, with 72.3 million units shipping between April and June 2020 (IDC, 2020). Monitor (NCS, 2020) and webcam sales also spiked, with the latter selling out in the UK at one point over lockdown (Baraniuk, 2020).

The active remaking of settings within homes in the image of the office, through shorter and longer-term rearrangements and acquisitions of materials, occurred alongside a reordering of homes as sites of eating and fitness. This reordering also depended on the acquisition of goods as part of producing places to 'practice':

We bought a nice new pan. It costs like 60 quid [...] so it's like the most I've ever spent on a pot [...] a new set of knives as well. We basically purchased a lot. (Aaron, 36, civil servant) 
This is a pre-copy-editing, author-produced PDF of an article accepted following peer review for publication in the Journal of Consumer Culture (JCC)

This example also aligns with more widespread trends. In the first three months of stay-athome orders, supermarket sales in the UK grew by 14.3\% (Jahshan, 2020). There was also a more than 200\% increase in chest freezer sales in late March (BBC, 2020).

While these trends could be explained in reference to attempts to 'batten down the hatches', Aaron and his partner Kate, like others, emphasised having the time to think about, plan and cook more 'experimental' and 'vivid' meals due to being at home more often and being unable to eat out. The increased purchasing of cooking equipment connected, in such instances, with attempts to create more elaborate meals to emulate eating out experiences. Such experiences are themselves varied thanks to the spatio-economic development of cities and towns, which have come to provide profligate opportunities to sample different cuisines of food (Aitchison et al., 2000).

Sales figures of fitness equipment similarly spiked during the lockdown, as did participation numbers in online fitness programmes (e.g., Joe Wicks) (Wood and Partridge, 2020). These trends emerged as an estimated 7,000 UK fitness centres were shuttered, meaning ten-million gym memberships were defunct (Wood, 2020).

In response, participants reported how they quickly sought out exercise equipment:

It was quite a lot to begin with, you know, we were kind of stocking up [...] I was trying to get weights; I got a turbo trainer for my bike. (Ben, 28, carpenter)

Others discussed purchasing equipment and making space and time for keeping fit, finding that they were no longer getting exercise through their commute, participation in team sports and/or going to gyms. Others still discussed participation in classes thanks to the acquisition of new materials and sessions moving online:

I got a Yoga mat for Pilates [...] I usually do Pilates, like an in-person class [...] The classes moved from being in person to a Zoom meeting kind of thing. (Devin, 30, accountant)

These responses can be understood to reflect the intertwined socio-spatial histories of work and exercise, where the broader transition to more sedentary lifestyles - actualised by the move from field, to factory, to office - led to the creation of more active forms and sites of exercise to counteract the implications of less strenuous lifestyles (Latham, 2015). With the socio-spatial dimensions of lockdown making everyday life evermore passive for many, materials with various material-spatial qualities were sought out to support exercising at home.

The typically bulky qualities of much exercise equipment, commonly found in gyms and associated with normative ideals of fitness, meant heavy demands were placed on finding and making appropriate and relatively fixed doing-places to keep fit. This typically resulted in the 
This is a pre-copy-editing, author-produced PDF of an article accepted following peer review for publication in the Journal of Consumer Culture (JCC)

reconstitution of gardens, garages and spare rooms as 'home' gyms, rather than living rooms and bedrooms:

In the garage - we've got a bit of a gym with an exercise bike, weights and a rowing machine [...] I've got quite a set up. (Ian, 61, police response caller)

We've got the Olympic weightlifting [bar...] with the bench, and [he] bought a kettlebell... That basically takes up the whole garden. (Kate, 50s, civil servant)

Echoing Schatzki's (1991) assertion that practices are constrained, conditioned to and anchored by a range of objects, the bulkiness of much gym-based exercise meant settings that commonly stand in reserve at home or are used less frequently were populated by bits of equipment and dedicated to a different set of uses.

These examples point to the types of instituted material-spatial qualities and dynamics that structured patterns of consumption and the related use and redesign of doing-places and settings across homes during lockdown. Drawing the examples together, it is clear that practices to do with office work, fitness and eating, carry material-spatial qualities that are rooted in settings and histories outside the home and that these structure the use of homes when they anchor there. Yet, material-spatial qualities alone did not determine how and where practice bundles re-rooted within homes; the affective qualities of practices also played constitutive roles.

\section{Satisfying instituted qualities of comfort}

Affective qualities of comfort also played key roles in structuring resource use and the ordering of homes as material-spatial arrangements during lockdown. Crucially, affective qualities of comfort differed across the practice bundles examined. We connect these differences with the socio-spatial histories of practice and ordering of instituted sites.

In the case of office construction, privacy emerged as a key feature of comfort. This was particularly the case for those participants who were working in spaces occupied (and/or travelled through) by other members of the household. This is intriguing given the communal history of offices and the contemporary shift to open-plan designs. As Littler (1978) shows, the rise of offices began in the 1900s and mirrored ideals associated with the Industrial Revolution. The first open-plan offices, in Taylorist design, sought to improve efficiency across businesses that did not rely on manual labour, by reflecting the organisation of the assembly line. Over time, offices gained further efficiency through the squeezing in of additional desks and more workers (Littler, 1978) allowing for managers to more easily scrutinize workers as they were in one place at one time. This history suggests that productivity and privacy are not understood to be mutually dependent in 'the' office. The same cannot be said, however, when office working re-rooted in homes. 
This is a pre-copy-editing, author-produced PDF of an article accepted following peer review for publication in the Journal of Consumer Culture (JCC)

Office work conducted in kitchens and in other shared settings of practice was particularly problematic:

I've moved upstairs. Working downstairs wasn't great, I was getting disturbed a lot [...]. And, you have the chair and the screen, it was taking up a lot more space on the kitchen table. [...] you have that left there, and then the four of you are kind of squished into two thirds of the table trying to have dinner. (Kate, 50s, marketing)

As this quote suggests, the movement of office-based work into the kitchen impacted both the performance of synchronous and asynchronous practices. The specificity of the kitchen table, as the doing-place for eating dinner with the family, and the disruption to eating caused by work materials left on the table, meant that, after a short period of time, performances of work had to move upstairs. Ingold's (2012) contention that materials come to take on the qualities of the practices that they are a part of is echoed here. In this case, even the mere presence of materials and related associations acted to dissolve meaningful boundaries between office working and eating.

Despite common understandings of privacy being associated with the sole occupancy of a room (or even the home), this did not always satisfy expectations of privacy and comfort linked with office work. For instance, though bedrooms are often seen as private spaces, this did not always neatly conform with or support appropriately 'private' performances of office work:

I could go in the bedroom [...] but I was really conscious of not wanting to be in a space that I'm in a lot when I'm [...] dealing with trauma. (Karren, 32, therapist)

Karren demonstrates how different types of office-based working carry different affectual qualities, with these impacting whether work could be carried out within the bedroom and bundle with sleeping (or not). It was important here, to keep the setting of sleeping separate from that of work (e.g., therapy), with elements of the participant's work (e.g., trauma) and normative positions around 'sleep hygiene' clashing. For other kinds of office work, with different affectual 'baggage', the privacy gained through working within the (new) setting of the bedroom superseded concerns around the bundling of work with sleeping practices.

The following quote helps make sense of these (a)synchronous dynamics:

[I]ndividual practices do not have intrinsic dimensions, features or temporal qualities. Instead, they are always bound up with other activity. What looks like a feature is rather an outcome of a practice's positioning. (Blue and Spurling, 2017: 31)

In the context of our research, attempts to be private, in order to feel comfortable while office working, were an outcome of otherwise unrelated performances of practices being spatially and temporally co-located (bundled), as opposed to privacy being an intrinsic feature of office work in and of itself. It is only because office working was performed by a practitioner at the 
This is a pre-copy-editing, author-produced PDF of an article accepted following peer review for publication in the Journal of Consumer Culture (JCC)

same time and/or in the same space as another practice, that privacy became a heightened feature or expectation of office work. Indeed, only those participants who had to share space with others not performing that same practice when working, raised the importance of privacy. For those who were home alone when working, privacy was only a feature when practices with 'incompatible' affectual dimensions were bundled together (e.g., therapy and sleeping in the bedroom; or noisy washing machines and working in the kitchen).

The importance of affectual compatibility also emerged in relation to practices other than office working, and these affective qualities went beyond privacy. Discussions with participants around exercise for instance - and particularly performances of Yoga and Pilates - emphasised the challenge of balancing expectations of privacy with bodily temperature. Such challenges are, in part, related to the clothing used in forms of exercise.

This morning I did some Yoga and then [went to] get a coffee. I walk in [to the living room] and I could see [my partner's] colleagues [on screen] <gasps> and, I've got my Yoga shorts on! It just makes me feel a bit uncomfortable... I'm in my Yoga gear and I've got four people looking at me. (Kathy, 50s, student support services)

Problems thus emerged when expectations around comfort and dress in Yoga did not align with expectations of dress for another's office work. Indeed, clothing which was appropriate to wear during performances of Yoga and in warm spaces, was not deemed appropriate when passing through the doing-place of 'the' office.

Further discussing how she decided when and where to do Yoga, Kathy emphasised the importance of temperature. As she explained: "it wasn't too hot one morning, so I thought - I'll risk being in the bedroom". Coupled with the quote above, this account suggests that multiple affectual facets of practices (e.g., clothing, privacy, and 'right' kinds of temperature) combine to shape where, when and how practices are performed across homes and whether practices can be bundled together (whether purposefully, or not).

Our examination of the bundling of office working and exercise highlights that it is not just instituted materials of practices that have been carried into homes, but also affective qualities and normative expectations linked with the ordering of specialised sites. These further shaped how and where performances unfolded across homes and demanded the configuration of particular and - at times - dedicated settings. It is in light of their instituted histories that the practices discussed are not only materially laden but also hungry for physical space.

While office working and fitness demanded that dedicated doing-places and settings were found and made in the home, for all of our participants a specialised setting for food preparation already existed: the kitchen. In the next section, we explore the 'lockdown working lunch' as a more distinctive case of an instituted practice in the re-making. 
This is a pre-copy-editing, author-produced PDF of an article accepted following peer review for publication in the Journal of Consumer Culture (JCC)

Re-making the working lunch

The history of lunch predates the Industrial Revolution, yet this period brought with it important collective changes that shaped the 'working lunch' into what we know today (Elias, 2014). Industrial factories and the urban ways of life that accompanied them heralded, for instance, significant changes to collective timing structures (Southerton, 2020). A noon-time meal became essential to sustain factory workers. Stalls appeared near factories, as pies and other forms of shop-bought and pre-cooked meals came to be regular expenditures in the late nineteenth century (Griffin, 2018). These features are not only mirrored in the design and production of food stuffs but also in contemporary urban centres, which are populated with places to pick up and/or have lunch.

The movement of the working lunch into homes and out of urban centres during the lockdown significantly changed this practice:

I've been having slightly more vivid lunches because we're making lunch... Instead of just going to the shop and buying a sandwich, like I would if I was in the office. [Now] we'll have scrambled egg with lots of veggies in them and things like this. [It] is a little bit more varied, I suppose, and it's probably a bit healthier. (Pac, 30s, marketing)

The 'sandwich' has long been a staple component of the working lunch in the UK (Elias, 2014). It is easy to carry, can be bought on a grab-and-go basis, involves relatively little mess, and requires no preparation infrastructure once bought. As Pac explains, however, when away from the office and the eateries that surround it, the sandwich was no longer the go-to option. Lunch instead took on different and varied forms, often becoming slower and more purposeful.

Having moved into the setting of the home, there were also different opportunities for bundling practices together with lunch. Participants discussed, for example, how lunch had become a more sociable affair, regularly involving others:

We haven't had a conversation about it you know, we are both at home, so we [just] have lunch together. (Mariana, 59, high school teacher)

Together, Pac and Mariana's accounts point to the specificities of offices and homes as sites of consumption, the connections between them, and the performance of practices that occur within them. The working lunch in its pre-lockdown form was largely held in place by the setting of the office and others that surround it. Offices are often encircled by eateries in much the same way as factories were in the nineteenth century. These provide convenient eating opportunities, requiring no preparation on the part of the consumer. The relationship of the meal of lunch to the site in which it was being consumed during lockdown likewise impacted the timing, duration and types of food stuffs consumed. As reported by our participants, doing the working-lunch at home meant that there was a greater deal of time dedicated to preparing and having lunch and the meal was often shared. 
This is a pre-copy-editing, author-produced PDF of an article accepted following peer review for publication in the Journal of Consumer Culture (JCC)

Crucially, the emergent features noted were a product of being at home and knitted into a particular material-spatial arrangement. While lunch during lockdown was still surrounded by working, the availability of material resources (i.e., infrastructures, foodstuffs, cooking equipment) and other practitioners (e.g., co-workers, children), presented new possibilities for more varied enactments. This availability of resources provided opportunities for practitioners to squeeze in other practices (e.g., socialising; parenting; watching television). In this way, the variety in performances of doing lunch at home can be understood as a product of the sited, bundled and related instituted qualities of a practice which enables and calls for more time dedicated to performance - in part due to being at home and in being able to prepare meals in the moment. The additional time and materials dedicated to the locked-down working lunch can thus be viewed as outcomes of ongoing and emergent forms of institutionalisation, developing because of stay-at-home orders and the sited (re)bundling of multiple practices and practitioners in homes. In this regard, though it is partly through the formation of relationships that practices are made obdurate (Shove et al., 2012), we have demonstrated how even established associations (e.g., between the working lunch and the office), made and remade over the past century, can be broken and reformulated in moments of disruption.

\section{Discussion: Instituted spikes, implications and possible responses}

Casting an imaginary bird's eye view across the UK, time-lapsed over the course of the lockdown, it is possible to envision the emergence and refinement of offices, gyms and more elaborate kitchen facilities, with various practices, related materials and affective expectations, re-rooting in homes. Whilst we have mobilised a language of uprooting and re-rooting to describe such changes, it is crucial to note that such processes are not self-contained and will continue to evolve. Given this dynamism, how can this particular moment of disruption be maximised to benefit sustainability ambitions? Responding to this question involves identifying troubling patterns of consumption, explaining how these arise and thinking about what could be done in response. We have identified several trends, arguing that these are the result of instituted and intersecting histories of practice bundles. In this section, we consider which bundles of practice might stay at home, related implications, and what could be done in response to mitigate spikes in consumption.

When it became clear that the lockdown would not be short-lived, people sought equipment as part of turning temporary sites of work into more permanent home-based offices. As stayat-home orders ease(d) in the UK, a mix of home and office working is emerging as a favoured approach (CIPD, 2021; Gratton, 2020; BBC, 2021a). Similar to the motivations for the emergence of open-plan offices in the 1900s (Littler, 1978), this shift to 'hybrid working' is mainly justified in terms of productivity and efficiency (Gratton, 2020). The implications of these instituted ideals for patterns of consumption and sustainability will depend on how hybrid models are implemented. Hybrid models may see commuting reduced and possibly offices shrinking in size, with hot desking becoming more prominent, yet this will 
This is a pre-copy-editing, author-produced PDF of an article accepted following peer review for publication in the Journal of Consumer Culture (JCC)

simultaneously depend on homes becoming specialised sites of office work. This will likely see a duplication of equipment (e.g., computers; monitors; webcams; desks; chairs), whilst also entailing the simultaneous heating and powering of homes and offices, as some employees WFH and others in the office.

Opportunities to maximise the sustainability benefits of hybrid models lie, in part, in the hands of businesses. Programmes of material redistribution could help mitigate the purchasing of equipment (e.g., redistributing office tech and supplies to homes). This moment of dramatic change further offers up an opportunity to rethink the temporal and material dynamics of office working, and how these help to form peaks and troughs in energy and resource demand. Normative and problematic values around office attire, heating and comfort (Shove, 2003) could, for instance, be tackled by employees welcoming the use of different forms of attire across seasons.

The instituted ordering of practices and specialised sites of fitness also helped to produce spikes in consumption during lockdown. Many people rushed to remake the home in the image of such sites. These efforts cannot be detached from the historical socio-spatial ordering of fitness practices. The global spread and popularity of weight training, for example, and the related multiplicity of gyms over the past century, meant that the pandemic intersected with particularly bulky and materially-laden forms of fitness. With gym and fitness studios reopening across the UK at the time of writing, it is difficult to say the extent to which homes will remain sites of exercise. The lockdown clearly spurred on the purchasing of fitness equipment, much of which remains in homes - 'ready-to-hand'. Online classes also remain popular (BBC, 2021b). This suggests that, particularly for those not in a position to visit specialised sites due to health, caring responsibilities and/or economic reasons, keeping fit at home could very well persist (BBC, 2021b).

The sustainability implications of the multiplication of keep fit equipment could be minimised through attempts to support the sharing of materials (e.g., fitness equipment libraries). Less materially-laden forms (e.g., bodyweight exercises) could also be encouraged through the provision and protection of communal spaces to exercise (e.g., outdoor calisthenic workout parks). However, in comparison to the role organisations could play in influencing the location of work (e.g., at home or at the office) and to an extent the use of materials, the instituted histories of keeping fit have more diffuse roots and steering practices in the ways suggested is admittedly a challenging proposition.

We also discussed how stay-at-home orders led to spikes in the consumption of cooking equipment. Participants reported how this connected with attempts to create more 'vivid' meals in the image of those experienced when eating out, as these histories were carried into homes and shaped consumption. This was possible as our participants were relatively affluent, had kitchens, financial resources, time, and space to support experimentation. 
This is a pre-copy-editing, author-produced PDF of an article accepted following peer review for publication in the Journal of Consumer Culture (JCC)

Extra material acquisition and specifically exotic ingredients tend to have increased air milage and carbon intensities (Berners-Lee, 2020). The extent to which the end of lockdown restrictions will temper related demands is again hard to say. In the UK, it is estimated that nearly 10,000 restaurants and pubs closed in 2020 and will not reopen (CGA, 2021), as many eateries in city centres rely on high commuter footfall. The closure of eateries, coupled with the favoured embrace of hybrid working, mean that the demand for new materials and ingredients could well persist. Like practices of keeping fit, eating habits have diffuse roots. This being the case, the links between WFH and lunch suggest organisations could take a lead in trying to steer the emergence of sustainable eating habits. Seasonal and local ingredients could be taken up more broadly and supported by organisations. Such support would challenge troubling trends and contribute to positive shifts, including the reported decline in household food waste during the first lockdown, which is largely attributed to increased meal planning and the use of leftovers (WRAP, 2020).

Our analysis also revealed that the (re)production of doing-places and settings within the home during lockdown involved a more widespread distribution of practices across homes. This spatial redistribution was a product of the forced squeezing of instituted practices and various qualities into homes. This has not only changed what homes are, but what may be expected of them in the future. The competition between practices for physical space can be linked, for example, with a movement out of cities and a demand for homes with bigger kitchens, 'spare' rooms, offices, garages, and gardens (Ruzicka, 2020; Zoopla, 2020). Based on our analysis, this can be understood as an outcome of practitioners seeking out sites that better accommodate the instituted, material-spatial and affectual baggage of practices. The discussed possibilities for (a)synchronous performances are important in this regard.

Reading these points in conjunction, the redefined boundaries of 'domestic' consumption illustrate how policies seen as little to do with resource use and climate change influence (un)sustainable ways of living (Royston et al., 2018). Locking-down policies and the stamp duty freeze (a tax payment related to buying properties), for example, has spurred on and supported the flow of people to larger homes across the UK (Osborne, 2020). Whilst trends of this type are particularly worrying given the correlation between resource use, the size of homes and energy consumption (Ellsworth-Krebs, 2020), they also point to a much wider range of actors and elements that can be targeted when trying to intervene in domestic consumption (Royston et al., 2018).

\section{Conclusion}

We began this article referencing research which outlined optimistic implications of the COVID19 pandemic, with Cohen (2020) discussing an opportunity to downsize the consumer economy. Taking inspiration from theories of social practice (Schatzki, 1996, 2002; Warde, 2005; Shove et al., 2012), we have complicated the narrative of downsizing. 
This is a pre-copy-editing, author-produced PDF of an article accepted following peer review for publication in the Journal of Consumer Culture (JCC)

We have specifically explained forms of consumption occurring during lockdown and at home as an outcome of the instituted material-spatial and affective qualities of practices. We drew attention to the ways in which qualities of office working, keeping fit and eating, which have various histories that are mirrored in the design of specialised sites, acted to shape where, when and how practices were performed and, in turn, demand for resources and physical space. Rather than simply downsizing demand, for certain cohorts, such as our (relatively) privileged sample, locking-down helped to produce new patterns of consumption that pose fresh sustainability challenges.

Recognising that various instituted histories and qualities of practice have taken on increasing significance for domestic consumption and that many changes look set to stick, future sustainability research should explore the types of dynamics discussed, identify emergent and problematic trends, and support the design of appropriate responses. This could involve examining other instituted practices, related histories, connections and spatial-temporal patterns of consumption and provision emerging in the wake of the pandemic. Doing so promises to maximise the sustainability benefits of this dramatic period of disruption. This is a 'not-so-easy' task, with practices having histories and lives of their own and simultaneously involving multiple human and non-human actors, institutions, and interconnected and coconstitutive relationships (Shove et al., 2012). Nevertheless, and as we have shown, fruitful opportunities may emerge to identify and mitigate the longer-term effects of locking-down and specifically those that are antithetical to sustainable transitions.

\section{References}

Akrich M (1992) The description of technical objects. In: Bijker WE and Law J (eds) Shaping technology/building society: studies in sociotechnical change. Massachusetts: The MIT Press, pp. 205-224.

Baraniuk C (2020) No end to Covid-19 webcam shortage. BBC News, 25 July, 20.

BBC (2020) Freezer sales heat up amid coronavirus stockpiling. BBC News, 10 March, 20.

BBC (2021a) No full-time return to the office for over a million. BBC News, 6 May, 21.

BBC (2021b) Covid exercise: 'I'll never go back to the gym again'. BBC News, 4 Jan, 21.

Berners-Lee M (2020) How Bad are Bananas?: The Carbon Footprint of Everything. London: Profile Books.

Blue S (2017) Institutional rhythms: Combining practice theory and rhythmanalysis to conceptualise processes of institutionalisation. Time \& Society, 28(3): 922-950.

Blue S and N Spurling (2017) Qualities of connective tissue in hospital life: how complexes of practice change. In: A Hui, T Schatzki and E Shove (eds) The Nexus of Practices: Connections, constellations, practitioners. London: Routledge, pp. 24-37.

Carethers, J (2021) Insights into disparities observed with COVID-19. Journal of Internal Medicine, 289(4): 463-473.

CGA (2021) Market Recovery Monitor: Review of GB pub, bar and restaurant supply. Available at: 
This is a pre-copy-editing, author-produced PDF of an article accepted following peer review for publication in the Journal of Consumer Culture (JCC)

https://info.cga.co.uk/hubfs/Market\%20Growth\%20Monitor/CGA AlixPartners\%20Market \%20Recovery\%20Monitor\%20January\%202021.pdf (accessed 10 May 20).

Chen K, Wang M, Huang C, Kinney PL and Anastas PT (2020) Air pollution reduction and mortality benefit during the COVID-19 outbreak in China. The Lancet Planetary Health 4(6), e210-e212.

Cheng, K, Sun, Y and Monnat, S (2020) COVID-19 Death Rates are Higher in Rural Counties with Larger Shares of Blacks and Hispanics. The Journal of Rural Health, 36(4): 602-608.

CIPD (2021) Planning for hybrid working. Chartered Institute of Personnel and Development. Available at: https://www.cipd.co.uk/knowledge/fundamentals/relations/flexibleworking/planning-hybrid-working\#gref (accessed 10 May 20).

Cohen MJ (2020) Does the COVID-19 outbreak mark the onset of a sustainable consumption transition? Sustainability: Science, Practice and Policy 16: 1-3.

Elias M (2014) Lunch: A History. Maryland: Rowman \& Littlefield.

Ellsworth-Krebs K (2020) Implications of declining household sizes and expectations of home comfort for domestic energy demand. Nature Energy 5(1): 20-25.

Gherardi S (2000) Practice-Based Theorizing on Learning and Knowing in Organizations.

Thousand Oaks, CA: Sage Publications.

Giddens A (1986) The constitution of society: outline of the theory of structuralism. Cambridge: Polity Press.

Gram-Hanssen K (2011) Understanding change and continuity in residential energy consumption. Journal of Consumer Culture 11(1): 61-78

Gratton L (2020) Four Principles to Ensure Hybrid Work Is Productive Work. MIT Sloan Management Review. Available at: https://sloanreview.mit.edu/article/four-principles-toensure-hybrid-work-is-productive-work/ (accessed 12 May 2021).

Griffin E (2018) Diets, hunger and living standards during the British industrial revolution. Past and Present 239(1): 71-111.

Hall MC, Prayag G, Fieger P and Dyason D (2020) Beyond panic buying: consumption displacement and COVID-19. Journal of service management. Epub ahead-of-print 31 July 2020. DOI: 10.1108/JOSM-05-2020-0151

Hand M and Shove E (2007) Condensing practices: Ways of living with a freezer. Journal of Consumer Culture 7(1): 79-104.

Hitchings R and Latham A (2017) How 'social' is recreational running? Findings from a qualitative study in London and implications for public health promotion. Health \& place 46: 337-343.

Hui A and Walker G (2018) Concepts and methodologies for a new relational geography of energy demand: Social practices, doing-places and settings. Energy research \& social science 36: 21-29.

IDC (2020) Traditional PC Shipments Continue to Grow Amid Global Economic Slowdown. Available at: https://www.idc.com/getdoc.jsp?containerld=prUS46691020 (accessed 10 December 2020).

Ingold T (2012) Towards an Ecology of Materials. Annual Review of Anthropology 41: 427-442. Jack T (2013) Laundry routine and resource consumption in Australia. International Journal of Consumer Studies 37(6): 666-674.

Jahshan E (2020) UK grocery enjoys biggest sales jump in 26 years. Retail Gazette, 27 May, 20. Latham A (2015) The history of a habit: jogging as a palliative to sedentariness in 1960s America. Cultural geographies 22(1): 103-126. 
This is a pre-copy-editing, author-produced PDF of an article accepted following peer review for publication in the Journal of Consumer Culture (JCC)

Latour B and Woolgar S (1979) Laboratory life: the social construction of scientific facts. West Sussex: Sage Publications, Inc.

Littler CR (1978) Understanding Taylorism. British Journal of Sociology 185-202.

Markard J and Rosenbloom D (2020) A tale of two crises: COVID-19 and climate. Sustainability: Science, Practice and Policy 16(1): 53-60.

NCS (2020) Employed persons working at home. National Compensation Survey, Bureau of Labour Statistics. Available at: https://www.bls.gov/news.release/atus.t06.htm (accessed 10 December 2020).

Nicola M, Alsafi Z, Sohrabi C, Kerwan A, Al-Jabir A, Losifidis C, Agha M, Agha R (2020) The socio-economic implications of the coronavirus pandemic (COVID-19): A review. International Journal of Surgery, 78: 185-193.

Nicolini D (2011) Practice as the site of knowing: Insights from the field of telemedicine. Organization Science 22: 602-620.

ONS (2020a). Coronavirus and homeworking in the UK: April 2020. Available at: https://www.ons.gov.uk/employmentandlabourmarket/peopleinwork/employmentandem ployeetypes/bulletins/coronavirusandhomeworkingintheuk/april2020 (accessed 10 December 2020).

ONS (2020b). Coronavirus and homeworking in the UK labour market: 2019. Available at: https://www.ons.gov.uk/employmentandlabourmarket/peopleinwork/employmentandem ployeetypes/articles/coronavirusandhomeworkingintheuklabourmarket/2019\#: :text=Do wnload\%20this\%20chart\&text=For\%20the\%2012\%2Dmonth\%20period,week\%20prior\%20 to\%20the\%20interview (accessed 10 December 2020).

Osborne H (2020) Pent-up demand after Covid lockdown fuels UK house sales surge. The Guardian, 4 September, 2020.

Peteri V (2017) Bad Enough Ergonomics. SAGE open 7(1): 1-11.

Phuong D and Reanne F (2021) Unequal burdens: assessing the determinants of elevated COVID-19 case and death rates in New York City's racial/ethnic minority neighbourhoods. Journal of Epidemiology and Community Health, 75(4): 321-326.

Reckwitz A (2002) Toward a Theory of Social Practices: A Development in Culturist Theorizing. European Journal of Social Theory 5(2): 243-263.

Reckwitz A (2017) Practices and their affects. In: Hui A, Schatzki T and Shove E (eds) The Nexus of Practices: Connections, constellations, practitioners. London: Routledge.

Rinkinen J, Shove E and Smits M (2017) Cold chains in Hanoi and Bangkok: Changing systems of provision and practice. Journal of Consumer Culture 19(3): 379-397.

Rinkinen J, and Jalas M (2016) Moving home: houses, new occupants and the formation of heating practices. Building research and information: the international journal of research, development and demonstration 45(3): 293-302.

Royston S, Selby J and Shove E (2018) Invisible energy policies: A new agenda for energy demand reduction. Energy Policy 123: 127-135.

Ruzicka (2020) Renters race to the suburbs: Bigger homes in commuter towns and villages are on trend as 34\% of tenants demand more space. This is Money, 14 September, 20.

Schatzki T (1991) Spatial Ontology and Explanation. Annals of the Association of American Geographers 81: 650-670. 
This is a pre-copy-editing, author-produced PDF of an article accepted following peer review for publication in the Journal of Consumer Culture (JCC)

Schatzki T (1996) Social practices: a Wittgensteinian approach to human activity and the social. New York, New York: Cambridge University Press.

Schatzki T (2001a) 'Introduction: practice theory', In: Schatzki T, Cetina K, and Von Savigny E (eds) The Practice Turn in Contemporary Theory. London: Taylor \& Francis Group, pp. 115.

Schatzki T (2001b) 'Practice mind-ed orders', In: Schatzki T, Cetina K, and Von Savigny E (eds) The Practice Turn in Contemporary Theory. London: Taylor \& Francis Group, pp. 42-55

Schatzki T (2002) The site of the social: a philosophical account of the constitution of social life and change. University Park, Pa: Pennsylvania State University Press.

Schatzki T (2005) Peripheral vision: The sites of organizations. Organization Studies 26: 465484.

Schatzki T (2006) On organizations as they happen. Organization Studies 27: 1863-1873.

Schatzki T (2014) Art Bundles. In: Zembylas T (eds) Artistic Practices: Social Interactions and Cultural Dynamics. Taylor and Francis, pp. 17-32.

Sheller M and Urry J (2000) The City and the Car. International Journal of Urban and Regional Research 24(4): 737-757.

Shove E and G Walker (2014) What is energy for? Social practice and energy demand. Theory, Culture \& Society 31(5): 41-58.

Shove E, Pantzar M and Watson M (2012) The dynamics of social practice: everyday life and how it changes. London: SAGE.

Shove E (2003) Comfort, Cleanliness and Convenience: The Social Organisation of Normality. Oxford: Berg.

Shove E (2016) Infrastructures and practices: networks beyond the city. In: Coutard O and Rutherford J (eds) Beyond the Networked city: infrastructure reconfigurations and urban change in the North and South. London: Routledge, pp. 242-258.

Shove E and Pantzar M (2005) Consumers, producers and practices: Understanding the invention and reinvention of Nordic walking. Journal of Consumer Culture 5(1): 43-64.

Southerton D (2020) Time, Consumption and the Coordination of Everyday Life. London: Palgrave Macmillan.

Sovacool B, Furszyfer Del Rio D and Griffiths S (2020) Contextualizing the Covid-19 pandemic for a carbon-constrained world: Insights for sustainability transitions, energy justice, and research methodology. Energy research \& social science 68: 101701.

Spurling N (2018) Matters of time: Materiality and the changing temporal organisation of everyday energy consumption. Journal of Consumer Culture. Epub ahead of print. DOI: 10.1177/1469540518773818.

Warde A (2005) Consumption and Theories of Practice. Journal of Consumer Culture 5(2): 131 153.

Welch D (2020) Consumption and teleoaffective formations: Consumer culture and commercial communications. Journal of Consumer Culture 20(1): 61-82.

Wood Z (2020) UK's 7,000 gyms prepare for post-lockdown health warning. The Guardian, 16 May, 2020.

Wood Z and Partridge J (2020) Britons go on shopping spree to ease grind of Covid-19 confinement. The Guardian, 28 May, 2020. 
This is a pre-copy-editing, author-produced PDF of an article accepted following peer review for publication in the Journal of Consumer Culture (JCC)

WRAP (2020) Citizens and food waste as lockdown eases. The Waste and Resources Action Programme. Available at: https://wrap.org.uk/resources/report/citizens-and-food-wastelockdown-eases (accessed on 9 May 2021).

Zoopla (2020) Home buyers shrug off recession fears as time to sell falls by almost two weeks. Zoopla, 27 August, 20. 